\title{
Visual evoked potentials to lateralised stimuli in two cases of callosal agenesis
}

\author{
MICHAEL D RUGG, A DAVID MILNER, CHRISTOPHER R LINES \\ From the MRC Cognitive Neuroscience Research Group, Psychological Laboratory, University of \\ St Andrews, Fife, Scotland, UK
}

SUMMARY Visual evoked potentials (VEPs) to lateralised light flashes were recorded from two acallosal patients. In one patient, these recordings were made while he performed a choicereaction time task, and in the other patient the VEPs were obtained during a simple reaction time task. In both cases the patient's VEPs from electrode sites contralateral to the visual field of stimulus delivery resembled those of controls. Their VEPs from ipsilateral sites were aberrant, however, in that while control subjects showed a smaller and slightly delayed ipsilateral N160 component, this was not discernible in the patients' data. It is concluded that the ipsilateral N160 relies for its generation on the transcallosal transfer of information processed initially by the contralateral hemisphere.

During the past two decades there has been considerable interest in the behavioural effects of section of the corpus callosum and other forebrain commissures, and a considerable body of knowledge about the resulting hemispheric disconnection syndromes has accumuluated.' This work has greatly contributed to the understanding of the specialisations of the two hemispheres and the role that the commissures may play in integrating their functions (for example ref 2). It would be of equal interest to study the sequelae of damage to the commissures which falls short of total disconnection, but which may be sufficient to cause impairment of interhemispheric processes. For example, although difficult to detect using anatomic imaging techniques such as CT scan, such damage (specifically, to the corpus callosum) appears to be a common consequence of head trauma. ${ }^{3}$ A technique allowing a quantitative assessment of callosal damage would appear to be an essential prerequisite for the systematic study of its role in the manifestation of post-traumatic cognitive deficits.

One possible means of investigating callosal function non-invasively in man is by recording visual

Address for reprint requests: Dr MD Rugg, Psychological Laboratory, University of St Andrews, Fife, K16 9JU, UK.

Received 27 March 1984 and in revised form 12 August 1984. Accepted 23 August 1984 evoked potentials (VEPs) elicited by lateralised stimuli. A number of such studies have been conducted previously (see ref 4 for a review). Few of these are satisfactory on methodological grounds, but the consensus among them is that VEP components occurring in the $100-200 \mathrm{~ms}$ latency range, and most prominently the $\mathrm{N} 1$ component (latency around $150-160 \mathrm{~ms}$ ), have shorter latencies and larger amplitudes when recorded from the hemisphere contralateral to the visual field of stimulus presentation, compared to homotopic sites over the ipsilateral hemisphere. (An important exception is the case of VEPs elicited by half-field checkerboard reversal, when a "paradoxically" larger P $\overline{100}$ component is observed over the ipsilateral hemisphere; this is thought to be caused by generators on the medial surfaces of the occipital lobes being oriented so as to produce a more extensive VEP field over the opposite hemisphere. ${ }^{45}$ ) Recently, Rugg, Lines and Milner ${ }^{6}$ have studied VEPs elicited by small, unstructured, lateralised light flashes in detail. They confirmed the findings of previous studies reviewed by Rugg, ${ }^{4}$ reporting that VEPs recorded from occipital sites showed reliable ipsilateral-contralateral latency differences of approximately $12 \mathrm{~ms}$ in a negative component peaking around $160 \mathrm{~ms}$ (N160). Rugg et al $^{6}$ further reported that lateral central sites yielded smaller (about 3-4 ms) and somewhat less reliable ipsilateral-contralateral differences. Two subsequent experiments ${ }^{7}$ have followed up these observations by examining the effects of 367 
changes in stimulus intensity on ipsilateralcontralateral $\mathrm{N} \overline{160}$ latency differences. Changes in intensity were found to affect these differences at occipital sites only, with less intense stimuli giving rise to larger ipsilateral-contralateral differences; the smaller differences observed between central sites were unaffected by the intensity manipulation. Our interpretation of these data is that the ipsilateral-contralateral differences observed between homotopic lateral electrodes reflect the time required for stimulus information to cross, via the corpus callosum, from a "directly" stimulated contralateral hemisphere to the "indirectly" stimulated ipsilateral hemisphere. The finding that these differences are smaller centrally than occipitally, and are differentially sensitive to changes in stimulus intensity, is taken as evidence that information from visual stimuli crosses the corpus callosum through at least two distinct channels of transmission. ${ }^{8}$

If the above interpretation of the ipsilateralcontralateral latency differences observed in the $\mathrm{N} \mathbf{1 6 0}$ component is correct, then VEPs elicited by lateralised stimuli may prove useful in assessing the functional integrity of the corpus callosum in patients in whom pathology is suspected. However, first it is necessary to test the obvious prediction that individuals totally lacking a corpus callosum should show absent or grossly abnormal ipsilateral N160 VEP components, as the major route by which inter-hemisphere transfer takes place is absent. The present study directly addresses this issue by reporting data from two cases of congenital absence of the corpus callosum.

\section{Method}

\section{Description of patients}

(1) $\mathrm{BF}$ is a 20-year-old male with a history of mild epilepsy, who was diagnosed as acallosal by CT scan at age 16 years. He had a full-scale WISC IQ of 86 at age 11 , and suffers from no other known structural neurological abnormalities. A series of behavioural investigations $\mathbf{s}^{4}$ (and Jeeves, Milner and Silver, in preparation) has demonstrated that BF shows the range of behavioural deficits typical of these patients. ${ }^{\prime \prime}{ }^{\prime 0}$ Most pertinent to the present report is the finding that behavioural estimates of the rate of interhemispheric transfer of a simple visual stimulus in this patient are considerably elevated compared to normal controls (ca $16 \mathrm{~ms}$ compared to $c a 2.5 \mathrm{~ms}$ ). At the time of testing he was receiving medication to control his epilepsy ( $100 \mathrm{mg}$ phenytoin twice daily), and had suffered no attacks for five years.

(2) KC is a 23-year-old female, who has been fully described elsewhere. "12 12 She was diagnosed as acallosal in 1970 by air encephalography and angiography. In 1979 a dermoid cyst was removed from the left ventro-medial frontal region. CT scans prior to and following the opera- tion confirmed the acallosal diagnosis. As in the case of BF, $\mathbb{\complement}$ she shows a highly elevated behavioural estimate of interhemispheric transmission time. ${ }^{1-13}$

\section{Procedures and controls}

$\mathrm{BF}$ and $\mathrm{KC}$ have been studied using the choice-reaction ${ }^{\top}$ time (CRT) procedure employed by Rugg et al, ${ }^{6}$ and KC요 has also been investigated in a simple reaction time (SRT) paradigm, which was also used in Experiment 2 of Lines, Rugg and Milner.' The data from the two patients in the choice task are very similar, and to illustrate the generality of the findings we shall report in detail on BF's data in the CRT task, and KC's data in the SRT task. In the former case the controls consisted of 10 healthy young adults who $\frac{\bar{\sigma}}{\bar{\omega}}$ were employed in the study of Rugg et al..$^{6}$ In the latter $\frac{\bar{S}}{\vec{T}}$ case, the controls consisted of 8 young adults drawn from the same population, who were employed in Experiment 20 of Lines et al.'

Stimuli and Tasks

CRT task: Stimuli consisted of flashes emitted by light- $\vec{\omega}$ emitting diodes (LEDs) situated $4^{\circ}$ lateral to fixation. They subtended a visual angle of $0 \cdot 33^{\circ}$, and when illuminated emitted light at a wavelength of $585 \mathrm{~nm}$ with an intensity? of $6 \mathrm{mcd}$. Two exposure durations were employed; GO stimuli were illuminated for 10 ms and NOGO stimuli for $\rightarrow$ $90 \mathrm{~ms}$. A GO/NOGO reaction time task was employed, which required subjects to make a finger push as fast as possible with the hand ipsilateral to the visual field in which 음 the GO stimuli occurred. In each experimental run $100-$ stimuli were exposed, appearing randomly in one or othęr visual field with an inter-stimulus interval (ISI) of $2 \mathrm{~s}$. The을. probability of occurrence of a GO stimulus was 0.24 , ant warning tone preceded stimulus onset by $600 \mathrm{~ms}$. This tas $ळ$ allows the collection of VEPs uncontaminated by moter responses, while encouraging a reasonable level of alert- $\square$ ness.

BF viewed a dim, constantly illuminated fixation light in a darkened room, with his head restrained by a chin rest and the index finger of each hand resting on laterally $\frac{\circ}{\mathcal{D}}$ positioned microswitches. He was given 100 practice trials $\varrho$ and a further eight blocks of 100 trials each, resulting in a $\overrightarrow{\vec{\sigma}}$ total of 304 NOGO and 96 GO stimuli being exposed in $\frac{0}{3}$ each visual field. The control subjects underwent an identical procedure, except that on every other run they responded with the hand contralateral to the field in which GO stimuli occurred. This manipulation had no effect on NOGO VEP waveforms, ${ }^{6}$ but for the sake of comparability? only the data from the ipsilaterally responding condition will be compared here with BFs.

EEG was recorded with silver/silver chloride electrodes from $\mathrm{Pz}, \mathrm{C} 3, \mathrm{C} 4, \mathrm{O} 1$ and $\mathrm{O} 2$ of the 10/20 system. ${ }^{13}$ An additional pair of electrodes, $\mathrm{LO} 1$ and $\mathrm{LO} 2$, were placed lateral to $\mathrm{O} 1$ and $\mathrm{O} 2,20 \%$ of the distance from $\mathrm{Oz}$ to $\mathrm{Fpz}$ on the left and right. All electrodes were referred to linked mastoids. EOG was recorded bipolarly from electrodes situated on the outer canthus of the left eye and above the $N$ right eyebrow. Amplifiers were set for $3 \mathrm{~dB}$ attenuation at $30 \mathrm{~Hz}$ and a $1 \mathrm{~s}$ time-constant, and the electrophysiological $\mathrm{N}$ data were averaged on-line at a sampling rate of 1 point per $3 \mathrm{~ms}$. Any epochs associated with blinks or saccades $\sigma$ were automatically rejected, and the EOG was averaged 
along with the EEG so that the success of this procedure could be verified. In addition, epochs associated with incorrect behavioural responses were also excluded from the averages.

SRT task: Stimuli consisted of flashes emitted by LEDs of the same size and at the same eccentricity as in the CRT task. When illuminated they emitted light with an intensity of $140 \mathrm{mcd}$ at a wavelength of $583 \mathrm{~nm}$. Exposure duration was $5 \mathrm{~ms}$. The task required subjects to make a finger push as fast as possible on a centrally located button when they saw a flash. The same hand was used throughout an experimental run, each of which consisted of 80 stimuli exposed randomly in the left and right visual fields. A warning tone preceded the onset of each stimulus by a randomly determined interval between $0.5 \mathrm{~s}$ and $1.5 \mathrm{~s}$. RTs outside the range $150-800 \mathrm{~ms}$ were treated as errors. This task allows the concurrent study of electrophysiological and behavioural measures of inter-hemispheric transfer.

The procedure was very similar to that employed in the CRT task. KC was given 80 practice trials, followed by eight experimental runs, four runs requiring responses from the right hand and four from the left hand. The controls experienced four such experimental runs (another four, administered in the same experimental session, were at a lower stimulus intensity, and are irrelevant to the present report).

EEG and EOG were recorded in an identical manner to the CRT task, with the exception that the sampling rate was increased to 1 point $2 \mathrm{~ms}$, and the high frequency cut-off was $3 \mathrm{~dB}$ down at $100 \mathrm{~Hz}$.

\section{Results}

VEP waveforms from the acallosal subjects are shown in fig $1(\mathrm{BF})$ and $2(\mathrm{KC})$. In each case, the grand average waveforms of the control sample, and those of the typical control subject, are also illustrated for comparative purposes. In addition to visual examination, an attempt was made to provide an objective measure of the degree to which the relationship betwen the contralateral and ipsilateral waveforms in the acallosals deviated from that found in the controls. The assumptions underlying the method is that, at homotopic lateral electrode sites, the ipsilateral $\mathrm{N} \overline{\mathbf{1 6 0}}$ component results from essentially identical processes to those generating $\mathrm{N} \overline{\mathbf{1 6 0}}$ contralaterally, but is delayed due to the transcallosal relay. A cross-correlation between the two components should consequently approach unity when this time delay is taken into account by "shifting" the ipsilateral waveform forward in time by the appropriate value. In the present studies, cross-correlations were computed between a $60 \mathrm{~ms}$ epoch straddling the contralateral $\mathrm{N} \overline{160}$ peak, and a $60 \mathrm{~ms}$ ipsilateral epoch which took into account the "shift" required to compensate for the time-cost of callosal transfer. For each task, pair of lateral electrodes, and visual field of stimulus delivery, the same shift value was applied to each of the controls' data and those of the acallosal subjects. The shift value used for each correlation was the mean $\mathrm{N} \overline{160}$ ipsilateral-contralateral difference observed in the control subjects, and derived from visually guided cursor measurement. The procedure therefore allows the assessment of the extent to which the waveforms of the acallosal patients are "deviant" when compared to those of the subjects in the control samples.

$B F$ : Table 1 summarises the control latency data for the $\mathrm{N} \overline{160}$ component in the CRT task, and shows the same data for BF from the electrode sites contralateral to the visual field of stimulus exposure. No ipsilateral measurements are given for $\mathrm{BF}$ because, as can be seen from fig 1 , no ipsilateral $N \overline{160}$ component is observable in that latency range in which it is found in control subjects. Instead, in the region of the ipsilateral waveform coincident with the following and contralateral $\mathrm{N} \overline{160}$ peak, there is evidence of a positive-going process, which culminates in a positive-negative complex around $220-250 \mathrm{~ms}$. While this might be interpreted as a delayed $\mathrm{N} \overline{160}$, inspection of the contralateral waveforms suggests the existence of a similar, though somewhat attenuated component, indicating that this later negativity may be bilaterally generated. Table 2 shows the results of performing the cross-correlation procedure described above on the data from $\mathrm{BF}$ and the controls. In the case of every channel pair/visual field combination, BF's values are significantly smaller than those of the controls', and in all but one case are negative.

$K C$ : The $\mathrm{N} \overline{160}$ latency data from the controls and $\mathrm{KC}$ are summarised in table 3 . As in the case of $\mathrm{BF}$, only contralateral $\mathrm{N} \overline{\mathbf{1 6 0}}$ components are tabulated for $\mathrm{KC}$, as inspection of her waveforms revealed no sign of an ipsilateral $\mathrm{N} \overline{160}$ corresponding to that observed in the controls. $\mathrm{KC}$ s data are qualitatively very similar to those from $\mathrm{BF}$, in that they are generally characterised by normal contralateral $\mathrm{N} \overline{160}$ components and, in the corresponding ipsilateral waveforms, a broad positive-going process which resolves into a negative component peaking, in her case, around $200 \mathrm{~ms}$. Although less clearly so than in the case of $\mathrm{BF}$, this later negativity may have a corresponding component in the contralateral waveform, seen as a "notch" on the rising limb of the $\mathbf{P} \overline{2}$ component from the occipital sites. On the assumption that this late ipsilateral negative peak is indeed a delayed $\mathrm{N} \overline{160}$, ipsilateral-contralateral latency differences were computed for each site/ visual field combination. In all six instances, these differences were significantly greater than those observed in the controls $(p<0.0001$ in five out of six instances, and $<0.005$ in the remaining 


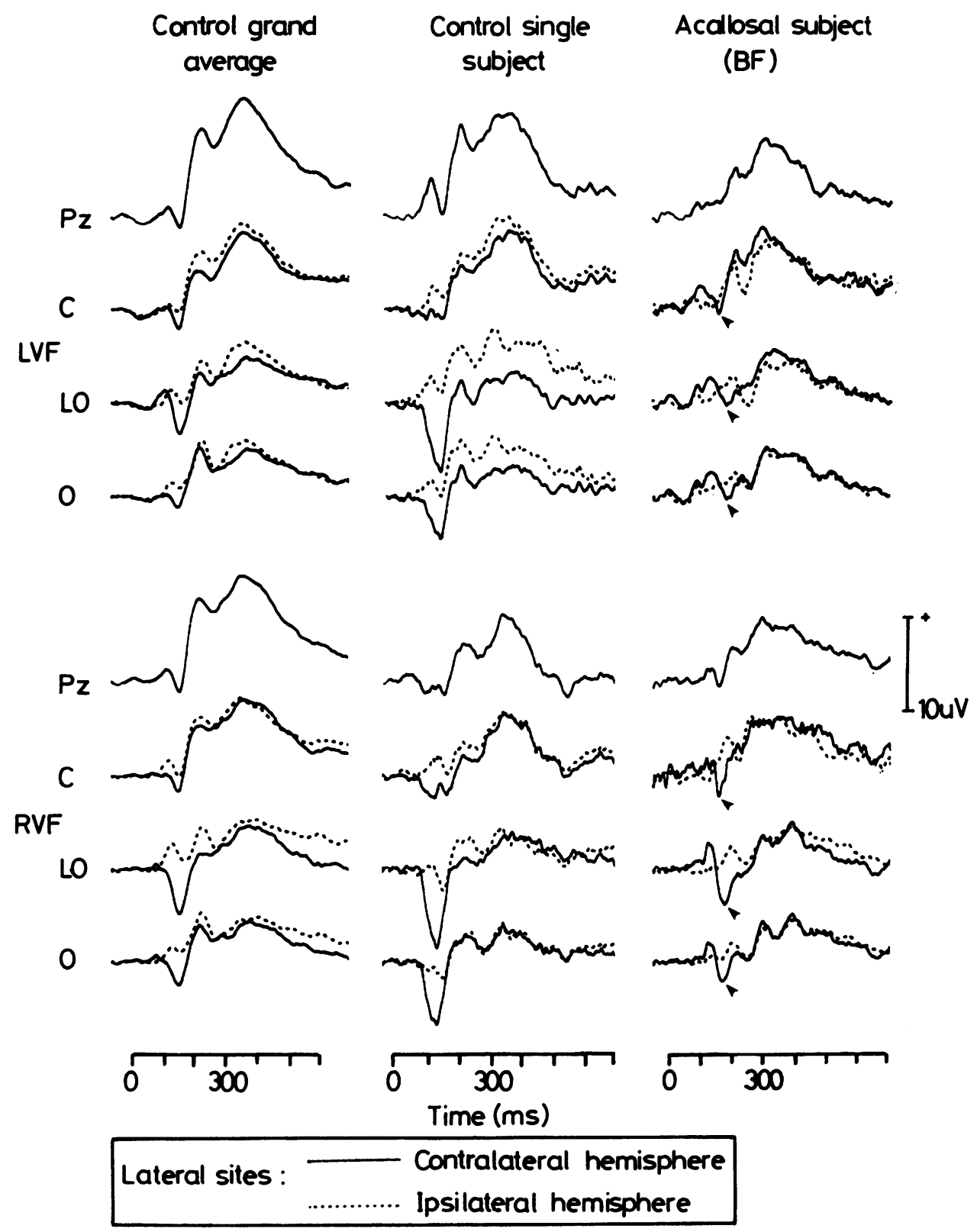

Fig 1 NOGO VEPs from BF, a typical control, and averaged across the control sample. The contralateral $N T 60$ component in $B F$ 's data is indicated by the arrows. $\mathrm{C}, \mathrm{LO}$ and $\mathrm{O}$ refer to $\mathrm{C}_{3} / C_{4}$ $\mathrm{LO}_{1} / \mathrm{LO}_{2}$ and $\mathrm{O}_{1} / \mathrm{O}_{2}$ electrode sites respectively. 
Visual evoked potentials to lateralised stimuli in two cases of callosal agenesis

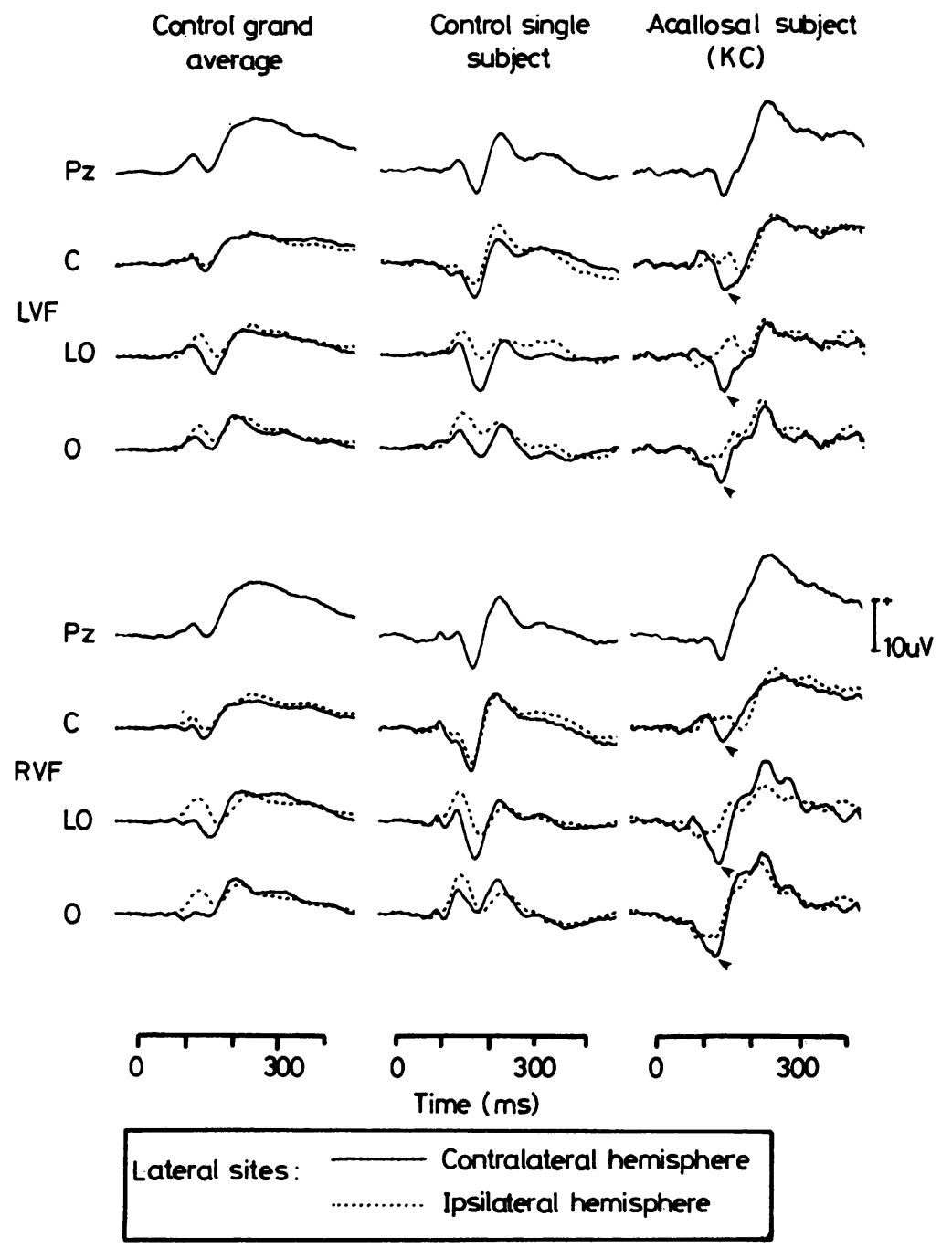

Fig 2 VEPs from $K C$, a typical control, and averaged across the control sample. The contralateral N160 component in KC's data is indicated by the arrows. C, LO and $O$ as for fig 1 .

Table 1 N $\overline{160}$ latency from control sample and from the contralateral sites of BF (CRT task)

\begin{tabular}{|c|c|c|c|c|c|c|c|c|c|c|c|c|c|c|c|}
\hline & & \multicolumn{7}{|c|}{$L V F$} & \multicolumn{7}{|c|}{$R V F$} \\
\hline & & $P z$ & $C_{3}$ & $C_{4}$ & $L O_{1}$ & $\mathrm{LO}_{2}$ & $O_{1}$ & $O_{2}$ & $P z$ & $C_{3}$ & $C_{4}$ & $L O_{1}$ & $\mathrm{LO}_{2}$ & $O_{1}$ & $\mathrm{O}_{2}$ \\
\hline $\begin{array}{l}\text { Controls } \\
(\mathrm{N}=10)\end{array}$ & $\begin{array}{l}\text { M } \\
\text { SD }\end{array}$ & $\begin{array}{r}159 \\
6\end{array}$ & $\begin{array}{r}156 \\
12\end{array}$ & $\begin{array}{r}157 \\
8\end{array}$ & $\begin{array}{r}170 \\
11\end{array}$ & $\begin{array}{r}161 \\
9\end{array}$ & $\begin{array}{r}171 \\
14\end{array}$ & $\begin{array}{r}154 \\
9\end{array}$ & $\begin{array}{r}159 \\
9\end{array}$ & $\begin{array}{r}150 \\
17\end{array}$ & $\begin{array}{r}159 \\
10\end{array}$ & $\begin{array}{r}159 \\
13\end{array}$ & $\begin{array}{r}175 \\
12\end{array}$ & $\begin{array}{r}155 \\
14\end{array}$ & $\begin{array}{r}171 \\
15\end{array}$ \\
\hline BF & $\mathbf{M}$ & 156 & & 153 & & 180 & & 177 & 156 & 156 & & 174 & & 165 & \\
\hline
\end{tabular}


Table 2 Ipsilateral-contralateral cross correlations in control sample and BF (CRT task: see text for details of procedure)

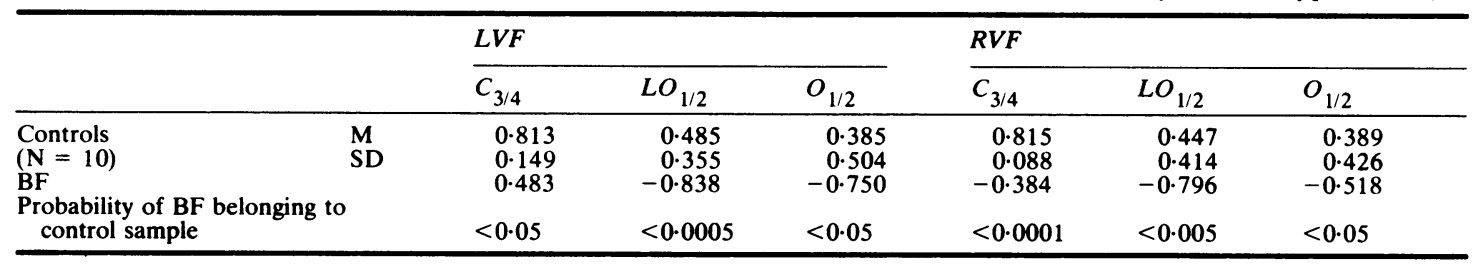

Table $3 N \overline{160}$ latency from control sample and from the contralateral sites of KC (SRT task)

\begin{tabular}{|c|c|c|c|c|c|c|c|c|c|c|c|c|c|c|c|}
\hline & & \multicolumn{7}{|l|}{$L V F$} & \multicolumn{7}{|c|}{$R V F$} \\
\hline & & $P z$ & $C_{3}$ & $C_{4}$ & $L O_{1}$ & $\mathrm{LO}_{2}$ & $O_{1}$ & $\mathrm{O}_{2}$ & $P z$ & $C_{3}$ & $C_{4}$ & $L O_{1}$ & $\mathrm{LO}_{2}$ & $O_{1}$ & $\mathrm{O}_{2}$ \\
\hline $\begin{array}{l}\text { Controls } \\
(\mathrm{N}=8)\end{array}$ & $\begin{array}{l}\text { M } \\
\text { SD }\end{array}$ & $\begin{array}{r}144 \\
7\end{array}$ & $\begin{array}{r}141 \\
6\end{array}$ & $\begin{array}{r}141 \\
7\end{array}$ & $\begin{array}{r}168 \\
11\end{array}$ & $\begin{array}{r}160 \\
7\end{array}$ & $\begin{array}{r}163 \\
8\end{array}$ & $\begin{array}{r}159 \\
10\end{array}$ & $\begin{array}{r}143 \\
12\end{array}$ & $\begin{array}{r}144 \\
8\end{array}$ & $\begin{array}{r}150 \\
13\end{array}$ & $\begin{array}{r}158 \\
9\end{array}$ & $\begin{array}{r}173 \\
9\end{array}$ & $\begin{array}{r}159 \\
10\end{array}$ & $\begin{array}{r}171 \\
8\end{array}$ \\
\hline $\mathrm{KC}$ & & 140 & & 146 & & 146 & & 140 & 140 & 146 & & 140 & & 132 & \\
\hline
\end{tabular}

Table 4 Ipsilateral-contralateral cross correlations in control sample and KC (SRT task: see text for details of procedure)

\begin{tabular}{|c|c|c|c|c|c|c|}
\hline & \multicolumn{3}{|l|}{$L V F$} & \multicolumn{3}{|l|}{$R V F$} \\
\hline & $C_{3 / 4}$ & $L O_{1 / 2}$ & $O_{1 / 2}$ & $C_{3 / 4}$ & $L O_{1 / 2}$ & $O_{1 / 2}$ \\
\hline $\begin{array}{l}\text { Controls } \\
(\mathrm{N}=8) \\
\mathrm{KC} \\
\begin{array}{l}\text { Probability of KC belonging to } \\
\text { control sample }\end{array}\end{array}$ & $\begin{array}{c}0.956 \\
0.029 \\
0.074 \\
<0.0001\end{array}$ & $\begin{array}{r}0.755 \\
0.402 \\
-0.808 \\
<0.0005\end{array}$ & $\begin{array}{l}0 \cdot 682 \\
0 \cdot 554 \\
0 \cdot 563 \\
\text { NS }\end{array}$ & $\begin{array}{r}0.895 \\
0.088 \\
-0.256 \\
<0.0001\end{array}$ & $\begin{array}{r}0.683 \\
0.278 \\
0.005 \\
<0.02\end{array}$ & $\begin{array}{l}0.717 \\
0.203 \\
0.757 \\
\text { NS }\end{array}$ \\
\hline
\end{tabular}

instance). Table 4 shows the cross-correlational data from $\mathrm{KC}$ and the controls in this task. In four out of the six cases, correlations are significantly lower than the controls. In the two other instances, high positive correlations are observed, and inspection of fig 2 indicates that these are because the previously noted ipsilateral positivity has an onset which is more or less contemporaneous with the peak of the contralateral $\mathrm{N} \overline{160}$.

Finally, it is worth noting that KCs RT data yielded an estimate of inter-hemispheric transmission time (the mean difference between "crossed" and "uncrossed" responses in each visual field) of $20.4 \mathrm{~ms}$. This is consistent with previous studies on this patient, ${ }^{11-13}$ and greatly exceeds the mean value of $1.8 \mathrm{~ms}$ observed in the controls; this latter value is in the range usually recorded for this task. ${ }^{15}$

\section{Discussion}

The data from these patients supports the hypothesis that the ipsilateral N $\overline{160}$ VEP component observed to lateralised flashes is dependent on the integrity of the corpus callosum. In both patients, VEPs from sites contralateral to the field of stimulus delivery contained clear $\mathrm{N} \overline{160}$ components in the same latency range as in controls. In contrast, ipsilateral sites yielded VEPs in which no N160 w observable analogous to that seen in the controls. The abnormality of the acallosals' ipsilateral VEPS in this latency range was confirmed by the crosscorrelational procedure employed, which indicated that 10 of the 12 correlations performed on the patients' data were significantly outside the normal range.

It is important to note that both patients' ipsilateral waveforms do show evidence of stimulusevoked activity. In addition to the relatively late, possibly bilateral, positive-negative complex clearly observable in ipsilateral waveforms, later regions also show a high degree of similarity to their contralateral counterparts. There are at least four possible reasons for this activity in the ipsilateral hemisphere. Firstly, some of the components may be generated by structures interconnected by surviving commissural systems which allow the ipsilateral hemisphere to gain access to stimulus information, and these may be related to the structures which mediate the transfer of the information allowing acallosals to make crossed RT responses. On the of basis of the finding that in $\mathrm{KC}$, and unlike normals, $N$ behavioural estimates of interhemispheric transmission time vary with stimulus intensity, Milner ${ }^{10} 11$ has suggested that this transfer process may be mediated 
by a sensorially coded pathway such as the anterior commissure. A second reason for the existence of ipsilateral VEP activity in the acallosal patients is that some components may be generated by "deep" sub-cortical sources which produce a diffuse bilateral electrical field at the scalp. Thirdly, it is possible that some ipsilateral activity is generated at the reference sites, and not at the ipsilateral scalp sites at all. While this possibility cannot as yet be ruled out in these patients, further work on normal subjects using a non-cephalic reference indicates that the mastoids are minimally active in these paradigms, and then only in the latency range of $N \overline{\mathbf{1 0 0}^{16}}$ (Rugg, Lines and Milner). Finally, the ipsilateral electrodes may be detecting some activity volumeconducted from the contralateral hemisphere. This may especially be the case at $\mathrm{O}_{1}$ and $\mathrm{O}_{2}$, which were the lateral electrodes nearest to one another and at which, in KC's data particularly, the ipsilateral and contralateral data are most similar. These issues will, we hope, be resolved by the investigation of VEPs in a wider range of patients, but they do not detract from the principal point of the current report, namely the importance of callosal pathways in the generation of the ipsilateral visual $\mathrm{N} \overline{160}(\mathrm{~N} 1)$ component in response to lateralised stimuli. This finding (1) lends support to Rugg et al' $\mathrm{s}^{6}$ interpretation of ipsilateral-contralateral N 160 latency differences in normals as being due to callosal transfer processes and (2) suggests that VEPs to lateralised stimuli may have a role to play in the detection of suspected callosal pathology.

This research is supported by the Wellcome Trust and the Medical Research Council of the UK. We thank Mr I Jacobson (Dundee Royal Infirmary) and Dr J Wilson.(Hospital for Sick Children, London) for their co-operation.

\section{References}

' Sperry RW. Lateral specialization in the surgically separated hemispheres. In: Milner B, ed. Hemisphere Specialization and Interaction. Cambridge Mass: MIT Press, 1975:5-20.

${ }^{2}$ Gazzaniga MS. Partial commissurotomy and cerebral localisation of function. In: Zulch KJ, Creutzfeldt GC, eds. Cerebral Localisation. New York: SpringerVerlag, 1975:133-7.

${ }^{3}$ Adams JH, Gennarelli TA, Graham DI. Brain damage in non-missile head injury: observations in man and sub-human primates. In: Smith WT, Cavanagh JB, eds. Recent Advances in Neuropathology. London: Churchill Livingstone, 1982:165-90.

${ }^{4}$ Rugg MD. Electrophysiological Studies. In: Beaumont JG, ed. Divided Visual Field Studies of Cerebral Organisation. London: Academic Press, 1982:129 45.

${ }^{5}$ Barrett G, Blumhardt L, Halliday AM, Halliday E, Kriss A. A paradox in the lateralisation of the visual evoked response. Nature 1976;261:253-5.

- Rugg MD, Lines CR, Milner AD. Visual evoked potentials to lateralised visual stimuli and the measurement of interhemispheric transmission time. Neuropsychologia 1984;22:215-25.

${ }^{7}$ Lines CR, Rugg MD, Milner AD. The effect of stimulus intensity on visual evoked potential estimates of interhemispheric transmission time. Exp Brain Res 1984;57:89-98.

${ }^{8}$ Milner AD, Lines CR. Interhemispheric pathways in simple reaction time to lateralised light flash. Neuropsychologia 1982;20:171-9.

Milner AD, Jeeves MA, Silver PH, Lines CR, Wilson J. Reaction times to lateralised visual stimuli in callosal agenesis: stimulus and response factors. Neuropsychologia 1985; in press.

${ }^{10}$ Milner AD. Neuropsychological studies of callosal agenesis. Psychol Med 1983;13:721-5.

"Milner AD. Simple reaction times to lateralised visual stimuli in a case of callosal agenesis. Neuropsychologia 1982;20:411-20.

12 Reynolds DM, jeeves MA. Further studies of crossed and uncrossed pathway responding in callosal agenesis: a reply to Kinsbourne and Fisher. Neuropsychologia 1974; 12:287-90.

${ }^{13}$ Lines CR. Nasotemporal overlap investigated in a case of agenesis of the corpus callosum. Neuropsychologia 1984;22:85-90.

${ }_{14}$ Jasper $\mathrm{HH}$. The ten twenty electrode system of the international federation. Electroencephalogr Clin Neurophysiol 1958;10:371-5.

${ }^{15}$ Bashore TR. Vocal and manual reaction time estimates of interhemispheric transmission time. Psychol Bull 1981;89:352-68.

${ }^{16}$ Rugg MD, Lines CR, Milner AD. Further investigation of visual evoked potentials elicited by lateralized stimuli: effects of stimulus eccentricity and reference site. Electroencephalogr Clin Neurophysiol 1985; in press. 